DOI 10.37882/2223-2974.2021.03.20

\title{
НАСТОЯЩЕЕ И БУДУЩЕЕ РАЗВИТИЕ ОБОРОННО-ПРОМЫШЛЕННОГО КОМПЛЕКСА РОССИЙСКОЙ ФЕДЕРАЦИИ
}

\section{PRESENT AND FUTURE DEVELOPMENT OF THE MILITARY-INDUSTRIAL COMPLEX OF THE RUSSIAN FEDERATION}

Yu. Mindlin

Summary: The article discusses the main processes of transformation of the military-industrial complex of the Russian Federation from the collapse of the USSR to the present day. The author highlights the main requirements for the formation of new approaches to conducting effective activities of defense industry enterprises in modern conditions. The article offers the main advantages and opportunities of clustering the military-industrial complex, taking into account the new challenges of our time (wars, competition, and the arms race). Emphasis is placed on the importance of combining the strategic goals of ensuring the country's state security with the economic feasibility of military industry production.

Keywords: cluster, competitiveness, military-industrial complex, military industry, security strategy, arms race, civil production, diversification, innovations in the defense industry.
И нновационное развитие мировой экономики, связанное с прогрессивными изменениями в технологии и формах и методах организации труда, нуждается в новых подходах к управлению производством и значительных затратах: материальных, интеллектуальных и финансовых. Российская Федерация унаследовала после распада Советского Союза почти 70\% предприятий, производивших оборонную продукцию. Обороннопромышленный комплекс (ОПК) России в значительной мере был интегрирован в союзные структуры и зависел от внешних заказов и объемов поставки комплектующих, материалов и сырья. Но так было только в самом начале пути.

Ведущими в Национальной экономике были такие отрасли (подотрасли):

- ракетно-космическая;

- судостроение;

- транспортная авиация;

- бронетанковая и инженерная техника;

- производство специальных радиотехнических систем.

Однако в России вначале пути развития ОПК не про-

\author{
Миндлин Юрий Борисович \\ К.э.н., дочент, ФГБОУ ВО «Московская государственная \\ академия ветеринарной медицины и биотехнологии \\ имени К.И. Скрябина» \\ mindliny@mail.ru
}

Аннотация: В статье рассмотрены основные процессы трансформации оборонно-промышленного комплекса Российской Федерации с момента распада СССР до наших дней. Автор выделяет основные требования к формированию новых подходов к ведению эффективной деятельности предприятий ОПК в современных условиях. В статье предложны основные преимущества и возможности кластеризации ОПК с учетом новых вызовов современности (войн, конкуренции и гонки вооружения). Сделан упор на важности сочетать стратегические цели обеспечения государственной безопасности страны с экономической целесообразностью производства ОПК.

Ключевые слова: кластер, конкурентоспособность, оборонно-промышленный комплекс, военная промышленность, стратегия безопасности, гонка вооружений, гражданское производство, диверсификация, инновации в ОПК.

изводились такие важные компоненты вооружений, как истребительная, штурмовая и бомбардировочная авиация, зенитно-ракетные комплексы, артиллерийское оружие и т.д. [6].

В 2006 г. в результате очередного процесса по реформированию ОПК было инициировано пересмотр принципов управления финансовыми потоками и собственностью ОПК. Главная проблема заключалась в существовании различных субъектов прав собственности и финансирования, то есть собственники предприятий оборонного комплекса (уполномоченные государственные органы, осуществляющие управления) не обеспечивали размещением на предприятиях государственных заказов, контрактами и работой эти предприятия, зато это выполнялось другими структурами, которые не имели прав собственности и не влияли на управление оборонными предприятиями. Как следствие - стали формироваться немалые финансовые потоки между торговыми посредниками, управляющими структурами и собственниками.

Сейчас проблема реструктуризации и дальнейшей трансформации ОПК остается одной из главных в деле 
национальной экономики Российской Федерации на рыночных началах. Значимость и актуальность этой проблемы обусловлены насущными потребностями, связанными с преодолением разрушительных процессов, которые происходят в оборонной промышленности; сохранением и развитием научно-технического и технологического потенциала; повышением социальноэкономической эффективности оборонного производства на основе новой государственной промышленной политики.

Успешное проведение реструктуризации предприятий, учреждений и организаций ОПК должно предусматривать создание благоприятных условий для товаропроизводителя, обеспечения надежных гарантий иностранным и отечественным инвесторам, выборочную государственную поддержку предприятий и научных организаций, наиболее весомых для оборонной отрасли.

Применение механизмов инновационного обновление в оборонной промышленности РФ стало объективной необходимостью, поскольку предприятия отрасли крайне нуждаются в комплексной модернизации за счет создания современной инновационной инфраструктуры в эпоху глобальной цифровизации и новых технологий.

Значительная часть предприятий, учреждений и организаций ОПК уже прошли этап акционирования, создание государственных холдинговых компаний, промышленно-финансовых групп, международных промышленно-финансовых групп, лизинговых компаний, консорциумов. Однако результаты производственной деятельности этих структур показывают, что большинство из них еще не достигло основной цели - обеспечение прибыльного производства. Это связано с отсутствием средств для модернизации производства, пополнения оборотного капитала, отсутствием эффективной нормативно-правовой базы и тому подобное [4].

Учитывая структурные изменения в системе экономических явлений и процессов, создание рыночно-ориентированных интегрированных структур, возникла необходимость перестройки и модернизации ОПК РФ, которые должны осуществляться за счет реформирования. Особенно в процессе военной гонки с США, а теперь еще и с Китаем.

Определяя круг предприятий, учреждений и организаций, остающихся в оборонном производстве, необходимо ориентироваться на те, в которых имеются следующие условия [3]:

- соответствие собственных возможностей планам реформирования Вооруженных сил и потребностям их в военной стратегии РФ;
- высокий экспортный потенциал, который даст возможность создавать высокотехнологичную и конкурентоспособную продукцию военного назначения;

- современные технологии, устойчивые кооперационные связи;

- минимально возможное перепрофилирование научно-технического и технологического заделов;

- хорошо решенные социальные аспекты.

В результате реформирования ОПК должно быть создано ядро высокотехнологичных предприятий промышленности, которые будут отвечать новой задачей военного строительства в стране и ее военно-технического сотрудничества с иностранными государствами, способного обеспечить также восстановление и ускоренное развитие производства конкурентоспособной гражданской продукции.

Структурная трансформация ОПК может быть реализована на макро- и микроуровнях. На макроуровне-как система в целом: должны быть определены масштабы, структура продукции и производственных мощностей, структура ОПК, в том числе структура мобилизационных мощностей; основные формы производств, соотношение государственного и негосударственного секторов оборонной промышленности; перечень производств, не подлежащих приватизации и привлекаемых к выполнению мобилизационных задач, а также должна быть реформирована структура системы государственного управления ОПК.

На микроуровне должна быть проведена производственно-технологическая реструктуризация ОПК и технологическая модернизация оборонных предприятий и организаций с целью формирования качественно новой производственно-технологической структуры, которая будет способствовать эффективному функционированию в рыночной среде.

Целью производственно-технологической реструктуризации должна стать консолидация оборонных предприятий, диверсификация и конверсия избыточных производственных мощностей оборонных производств, интеграция производства продукции военного и гражданского назначения.

Реструктуризация ОПК должна осуществляться исходя из потребности решения на сегодня и ближайшую перспективу таких основных задач [7]:

- поддержка на основе имеющегося научно-технического и производственного потенциала необходимого технического уровня боеспособности вооруженных сил с ориентацией в перспективе на организацию собственного производства с замкнутым циклом; 
- расширение экспорта продукции военного назначения на основе развития наукоемких конкурентоспособных производств.

Необходимо осуществить техническое переоснащение производственной, технологической и экспериментальной базы ОПК для перепрофилирования или ликвидации бесперспективных предприятий, создание условий для углубленной интеграции оборонного и гражданского сектора экономики, международной кооперации и интеграции.

Технологическая модернизация должна проводиться с учетом:

- перехода к интегрированной компьютеризации на всех этапах жизненного цикла изделий;

- внедрение прогрессивных технологий производства новых материалов и их обработки;

- развития перспективных информационных технологий и внедрения современной элементной базы;

- создание энергосберегающих технологий, перспективных источников энергии и силовых установок различного назначения.

Основными направлениями структурной перестройки ОПК являются:

- приведение структуры и системы управления ОПК в соответствие с современной рыночной модели хозяйствования;

- создание экономически эффективных пропорций между отраслями ОПК, продукция которых должна стать конкурентоспособной на внешнем и внутреннем рынках;

- разработка экономического механизма стимулирование инвестиционных и инновационных процессов в ОПК, предусматривающих структурные сдвиги;

- формирование совместно с местными органами исполнительной власти современной региональной отраслевой структуры, определение направлений гражданской диверсификации предприятий ОПК;

- формирование стратегических альянсов и создание интегрированных структур, которые обеспечивают весь производственный цикл изделий, в том числе: вертикально интегрированных структур (транснациональных и национальных промышленно-финансовых групп, концернов, холдингов и тому подобное), которые охватывают весь технологический цикл производства продукции;

- полифункциональных интегрированных структур (транснациональных и национальных промышленно-финансовых групп, концернов, холдингов т. п.) для обеспечения внутренних и внешних ко- операционных поставок составляющих систем и компонентов к продукции военного и двойного назначения;

- горизонтально интегрированных территориальных научно-технических структур (технополисов, технопарков, бизнес-инкубаторов и тому подобное) на базе научных организаций и предприятий ОПК, научно-исследовательских учреждений, высших учебных заведений и банков для внедрения в производство высоких технологий, коммерциализации научно-технических разработок, выполнения программ развития регионов и программ реструктуризации предприятий ОПК.

Стратегические альянсы и интегрированные структуры (холдинги, промышленно-финансовые группы и тому подобное) в ОПК формируются по принципу экономической целесообразности в процессе реорганизации и реструктуризации предприятий. Структурные реформы и модернизация ОПК дадут возможность реформированным вооруженным силам соответствовать следующим требованиям [11]:

- оптимальные численность и масштабы;

- оснащенность современными системами разведки, поражения, противодействия и защиты;

- постоянное совершенствование;

- не обремененность для экономики государства;

- возможность надежной защиты от высокоточного оружия, оружия созданного на новых физических принципах, средствах массового поражения, в том числе химического и биологического оружия;

- преимущественная ориентация на использование мобилизационных возможностей и модульных трансформаций и тому подобное.

Одним из основных направлений реформирования ОПК в России может быть сочетание промышленного и финансового капитала производственных структур. Как свидетельствует мировой опыт, именно таким путем можно эффективно решить ключевые проблемы, связанные с налаживанием кооперационных и производственно-технологических связей, надежного инвестирования предприятий-производителей, повышения конкурентоспособности продукции, обеспечения ее устойчивого снабжения и сбыта.

По мнению автора, реформирование ОПК должно происходить путем реформирования технологических кластеров, что утверждает и современная экономическая теория, в которой значительное внимание уделяется проблемам организационно-экономической кластеризации. Свой системный развитие теория промышленных кластеров нашла в работе профессора Гарвардского университета Майкла Портера «Конкурентные преимущества стран», опубликованном в 1990 г., где он предложил теорию национальной конкуренто- 
способности. В рамках современного кластера происходит управление знаниями как условие формирования экономического развития, осуществляемый оборот знаний (фундаментальных, технологических, технических, естественно-научных, гуманитарных, экономических) составляет основу комплексных технологических решений и новых форм управления системами промышленного производства [12].

Промышленный кластер - это сконцентрированные по географическому принципу группы взаимосвязанных компаний, специализированных поставщиков, поставщиков услуг, фирм в соответствующих отраслях, а также связанных с их деятельностью организаций (университетов, агентств по стандартизации, а также торговых объединений) в соответствующих отраслях, конкурирующих, но вместе с тем работающие совместно.

Как правило, во главе кластера находятся ключевые компании, которые генерируют ресурсы для развития новых рыночных ниш и экспортируют инновационную продукцию и услуги за пределы соответствующей территории. На условиях долгосрочной производственной кооперации с ведущей компанией работает большое количество поставщиков отдельных компонентов, оборудования, материалов, услуг. К главным факторам, побуждающим предприятия к кооперации в инновационной сфере, относятся: растущая комплексность современной технологической базы, требующей все большей компетентности и дополнительных знаний в Соединенных технологических сферах; ускорение технологических циклов; увеличение стоимости и риска инноваций [8].

Значимость технологических кластеров будет расти в ходе дальнейшей эволюции экономики и увеличения доли инновационной составляющей. Это связано с организацией процессов Технодинамики однотипных технологических систем в рамках нового технологического уклада на основе преобразования и замещения новыми техническими решениями значительных массивов отечественных промышленных производств. Именно развитие кластеров позволяет ускорить темпы развития существующего бизнеса и повышать интенсивность появления новых компаний в пределах соответствующего кластера.

Важной отличительной чертой кластера в общей модели производственно-кооперационных и других взаимодействий субъектов хозяйствования являются факторы инновационной ориентированности и интегрирующего продукта или услуги. Кластеры, как правило, формируются там, где осуществляется или ожидается прорывное продвижение в области техники и технологии производства и последующего освоения новых рыночных ниш.
Кластерный подход позволит повысить эффективность взаимодействия частного сектора, государства, торговых ассоциаций, исследовательских и образовательных учреждений в инновационном процессе. Он может служить основой для конструктивного диалога между представителями предпринимательского сектора и государства с целью выявления проблем развития науки и производства, путей наиболее эффективной реализации имеющихся инвестиционных возможностей и необходимых мер государственной политики.

Создание кластеров является одной из эффективных организационных форм работы. Основная идея формирования кластера состоит в том, чтобы на основе научно обоснованных и технологически реализуемых комплексных решений, а также коммерческих механизмов создать условия для модернизации промышленности высоких переделов (разработка приборов нового поколения, машиностроение, сверхчистые материалы, нанотехнологии и др.) и тем самым подготовить комплексные производственно-технологические пакеты для выгодных инвестиционных вложений [13].

В теории определены признаки кластера, которые экономисты называют правилом четырех «К» [9]:

1. концентрация предприятий одной или смежных отраслей в одной географической точке;

2. конкурентоспособность выпускаемой ими продукции;

3. конкуренция за завоевание и удержание клиента;

4. кооперация с высокой степенью развитости.

Формирование кластеров возможно как в условиях масштабной, так и небольшой по объемам экономики. Они возникают на национальном, региональном и муниципальном уровнях. Кластеры как вид сложной многовекторной организации в эпоху глобализации представляют собой типичную рыночную структуру мировой экономики [14].

Нередко центром формирования кластеров выступают университеты (институты, учебные заведения) или группы научно-исследовательских структур и научных учреждений. Создание новой формы объединения предприятий и организаций инновационно-технологических (высокотехнологичных) кластеров обуславливается тенденциями развития мировой конкурентоспособной экономики (глобальной экономики) [2].

В состав типового технологического кластера обычно входят следующие территориально близкие элементы, как «якорный» предприятие (крупное, часто градообразующее), предприятия-спутники (более мелкие производители и поставщики, транспортные организации и торговые сети), один или несколько профильных учебных заведений (или система вертикально интегрированных 
учреждений) и профильные научно-исследовательские институты [1].

Предприятия-участники кластеров насчитывали на 2009 г., 2300 исследователей, 56 действующих исследовательских проектов и имели 90 млн. евро ежегодной государственной поддержки [5]. В России также начались процессы формирования кластеров.

В рамках кластеров научно-технологическое взаимодействие происходит в трех основных направлениях:

- разработка R\&D (исследования и разработки) проектов по основному типу деятельности;

- разработка инновационных технологических платформ;

- развитие инновационной инфраструктуры, привлечение и поощрение к инновационному бизнесу других участников путем создания совместных предприятий и услуг.

Сеть кластеров является наиболее результативной средой для обмена технологиями, совместными НИОКР и маркетинговыми исследованиями. Высокая степень интегрированности в сетевую среду побуждает компании к поддержанию собственной инновационной активности, предоставляет возможности для апробации своих идей. Концентрации компаний, ориентированных на производство высокотехнологичной конечной продукции, получили название «инновационные кластеры» [4].

Военно-промышленные кластеры РФ занимаются разработкой и производством широкого спектра военной и гражданской продукции: высокоточных артиллерийских боеприпасов и артиллерийских выстрелов различного назначения, реактивных систем залпового огня, неуправляемых авиационных, малокалиберных боеприпасов, авиационно-бомбовых средств поражения, боевого автоматического и снайперского оружия, управляемых артиллерийских снарядов и пр.

Научно-исследовательский потенциал военного инновационного технополиса «Эра» (Анапа) выходит на проектную мощность. В настоящее время резиденты и партнёры «Эры» работают над 55 научно-исследовательскими проектами. Они реализуются как в инициативном порядке, так и в рамках гособоронзаказа (ГОЗ). Основное внимание уделяется разработкам в сфере искусственного интеллекта (распознавание образов, создание технологии нейронных сетей и интеллектуальных систем обработки данных).

Также предприятия технополиса специализируются на проектах в областях энергообеспечения (создание мощных портативных источников электричества), робототехники, информационной безопасности, биотехнических систем (комплексы медицинского назначения) и наноматериалов.

Президент России подчеркнул: «Между тем нам важно двигаться дальше и уже сегодня начинать планировать разработку и выпуск перспективных образцов вооружения и техники на будущее, которые определят облик Вооруженных сил России на длительную перспективу, на предстоящие десятилетия». Многое зависит и от возможностей самих предприятий оборонно-промышленного комплекса (ОПК). Новая ГПВ на десятилетний период до 2033 года, начиная с 2024 года, будет призвана продолжить модернизацию военной техники и превзойти уже созданные образцы. Вопрос ценообразования в ОПК и его совершенствование является одним из важнейших условий дальнейшего стабильного развития

Сейчас в технополисе работают 26 предприятий. В их числе Национальный исследовательский центр «Курчатовский институт», концерн «Калашников», ПАО «Компания «Сухой», ПАО «Туполев», АО «Концерн радиостроения «Вега», МГТУ имени Баумана, АО «МЦСТ» (разработка процессоров «Эльбрус»). Свои лаборатории и офисы В «Эре» планируют разместить 45 организаций (Военно-медицинская академия имени С.М. Кирова, холдинг «Вертолёты России», РСК «МиГ» и другие) [10].

Одна из ключевых задач, возложенных на «Эру», импортозамещение в сфере программно-аппаратного обеспечения, ну а остальные участники кластера продолжают решать и развивать поставленные стратегические задачи по обеспечению безопасности страны.

\section{Выво $\Delta ы$}

Формирование технологических кластеров при реформировании ОПК предоставит возможность за счет: повышения эффективности взаимодействия государства, частного сектора, торговых ассоциаций, исследовательских и образовательных учреждений в инновационном процессе; создание условий для модернизации промышленности высоких переделов (разработка приборов нового поколения, машиностроение, сверхчистых материалов, нанотехнологий); подготовки комплексных производственно-технологических пакетов для выгодных инвестиционных вложений содействие инновационному развитию ОПК; осуществление прорывного продвижения в области техники и технологии производства и последующего освоения новых рыночных ниш, создать модернизированный на инновационной основе ОПК, который будет способен своевременно, качественно, в требуемых объемах и в соответствии с номенклатурой обеспечивать оборонные потребности государства.

В целом, впервые со времен Второй мировой войны Россия оказалась в совершенно уникальной ситуации, когда не мы догоняем США, а США догоняют нас. В от- 
личие от всего, что было раньше, когда нашей стране, начиная с создания собственной атомной бомбы, приходилось постоянно искать адекватный ответ на появление в США какого-то нового вида вооружений, Россия добилась военного преимущества перед своим потенциальным противником. И теперь в ее интересах, чтобы эта «игра в догонялки» продолжалась как можно дольше, чтобы удалось как можно дольше удерживать это преимущество и на долгие годы надежно обезопасить себя от любых неприятностей. Время покажет, как с этим вызовом справится Россия, и кто преуспеет в этом соперничестве.

\section{ЛИТЕРАТУРА}

1. Бирюков А.В. Кластерная политика как фактор повышения конкурентоспособности предприятий оборонных отраслей промышленности // Транспортное дело России. 2009.№ 3.

2. Бирюков А.В. Формирование инновационных кластеров в высокотехнологичных отраслях промышленности: на примере ОПК России: автореф. дис. ...д-ра экон. наук. М., 2009.

3. Булатов А.Н. К вопросу о соотношении промышленной кооперации, концентрации, специализации и кластеризации // Российский экономический интернет-журнал: Интернет-журнал АТиСО / Акад. труда и социал. отношений : электрон. журн. - М.: ATиC0, 2010-10 URL: http: //www.e-rej. ru/Articles/2010 / Bulatov8.pdf.

4. Войнаренко М. Кластеризация в структуре предпринимательства, экономического сотрудничества и привлечения инвестиций. URL: http://www.unece. org/ie/wp8/documents/voynarenko. pdf.

5. Вопросы Федерального агентства по поставкам вооружения, военной, специальной техники и материальных средств: Указ Президента Российской Федерации от 14 мая 2010 г. № 589 // Рособоронпоставка. URL: http://www.rosoboronpostavka.ru/upload/iblock/db1/ukaz_140510_589.pdf.

6. Голиченко 0.Г. Национальная инновационная система России: состояние и пути развития. М.: Наука, 2006. С. 249-250.

7. Линьков А.Р., Козырев Е.Н. Технологические кластеры как основа развития наукоемких отраслей промышленности // Труды молодых ученых. 2011. №2. C. 169-174.

8. Москвин В. Россия приступила к формированию новой Госпрограммы вооружений // Независимое военное обозрение. 4.10.2018.

9. Портер М. Конкуренция. М.: Издательский дом «Вильямс», 2002. 496 с.

10. Прелин И. Чем ответят США на новое оружие, созданное в России // Российская газета. 21.10.2018.

11. Every Combined Arms Army Will Receive an Engineering Assault Brigade by 2020 // TASS Online, 2 December 2015. URL: http://tass.ru/armiya-i-opk/2492454.

12. Lester G., Bartles Ch. K. The Russian Way of War: Force Structure, Tactics, and Modernization of the Russian Ground Forces // Fort Leavenworth, KS: Foreign Military Studies Office, 2016. P. 10-12.

13. Semenchenko I. G. The State of and Problems for the Preservation and Development of the Military Industrial Complex of the Russian Federation // Journal of the Academy of Military Sciences. Vol. 3. No. 56. 2016. P. 111.

14. Tomas M., Roffey R. The Russian Defence Industry and Procurement / Russian Military Capability in a Ten-Year Perspective-2016, F0I-R-4326. December 2016, p. 172.

(с) Миндлин Юрий Борисович (mindliny@mail.ru). 